\title{
Community Redefined: School Leaders Moving from Autonomy to Global Interdependence through Short-Term Study Abroad
}

\author{
Janis B. Fine
}

Loyola University Chicago

\section{Krista W. McNamara \\ Loyola University Chicago}

\section{Introduction}

In times of increased global interdependence, producing inter-culturally competent school leaders who can engage in informed, ethical decisionmaking when confronted with problems that involve a diversity of perspectives is becoming an urgent leadership priority. Helping school leaders form and internalize a global perspective requires today's leadership preparation programs to assist future leaders in developing the capacity to think with complexity taking into account multiple cultural perspectives. With the growing knowledge that every action has an impact on others, school leaders must develop the disposition and perspective on which to base arguments for activist stances and tools to diagnose where positive policy and other interventions can be made for groups of disenfranchised and underserved students within the global educational community.

Today's educational leaders now know a great deal more about leading in a cross-cultural environment than they did in previous years. Effective teaching strategies and professional development programs have been identified, clarified, and developed to take advantage of diversity and to weave stronger, more united communities. Leadership preparation programs focusing on the nature of culture, race, class and gender relations in our society have provided leaders with a theoretical framework.

Yet, while an understanding of cultural patterns, social stratification mobility, principles of human development, and racial dynamics are often cited as markers of successful student preparation for leadership for global interdependence, these learning outcomes are often poorly defined and not well integrated into the curriculum for educational leadership. Study abroad, the primary mechanism by which students experience foreign cultures, has 
become a seminal vehicle for global learning. Education abroad has become an increasingly important educational program experience in global learning and development, intercultural competence, intercultural maturity, and intercultural sensitivity. "Education abroad has considerable potential in providing an environment that results in value added to student global learning and development" (Braskamp, Braskamp \& Merrill, 2008, p.1) However, the vast majority of educational leadership students lack access to high quality study abroad opportunities.

\section{Purpose}

This paper will present a framework for how to use global learning to develop in today's educational leaders the conceptualization and disposition to bring about the revolutionary changes that eliminate marginalizing practices in schools. By providing a global framework to guide this development, tomorrow's educational leaders will be provided with the learning they need to address the problems they will face in the future. Such a strategy aims to revitalize educational leadership preparation programs and increase student engagement by showing the relevance of global knowledge to education's most urgent social, ethical, and civic challenges.

Specifically, the purpose of this paper is:

1. To measure and describe changes that occurred during a two week study abroad experience in Rome. The data represents changes over three consecutive years, 2008, 2009, and 2010, in cognitive, intrapersonal, and interpersonal dimensions as measured by the Global Perspectives Inventory (GPI) and through a reflective openended survey.

2. To discuss the areas of most significant student growth; 1) intrapersonal/identity which is characterized by a level of awareness of one's unique identity and respect for and acceptance of cultural perspectives different from one's own 2) interpersonal/social responsibility which is characterized by interdependence and a commitment to the welfare of the larger community, with the larger community now being a global and pluralistic one.

3. Discuss how these two areas of growth continue to manifest and impact their daily actions.

4. To argue based on the results, that study abroad is an effective educational experience for school leaders to develop global perspective. 


\section{Rationale}

In the Culturally Proficient School: An Implementation Guide for School Leaders (2005) it is argued that culturally competent school leaders understand that effective leadership in a diverse environment is about changing the manner in which we work with those who are culturally different from ourselves. Personal transformation that facilitates organizational change is the goal of cultural competence. For educational leaders whose goal it is to transform their schools and districts into pluralistic, inclusive environments, they must first be willing to look deeply into their own tacit assumptions about the diverse students with whom they work. Further, leading effectively in a diverse environment is not about changing others; it is about our own personal work (Lindsey, Roberts \& Campbelljones, 2005).

Embedded in this viewpoint is an emphasis on higher-ordered learning and its relation to intellectual openness and the ability to adopt a critical perspective on one's own as well as other's beliefs, values and positions. Another assumption supported by the literature is that global perspectives would be more developed for people who have studied abroad (Astin, 2001; Pascarella $\&$ Terenzini, 2005). Examining the standards and policies set in place for educational leaders offers a glimpse of the values instilled in the educational system and where global interdependence fits into the expectations of school leaders. Established in 1996, and then updated in 2008, the Council of Chief State School Officers (CCSSO) advanced a set of standards through the Interstate School Leaders Licensure Consortium (ISLLC), a group representing the main constituents involved in the licensing and preparation of school leaders. In 2002, the National Council for Accreditation of Teacher Education (NCATE) adopted the standards for accrediting school administration programs. While these standards did not explicitly establish the expectations for the holistic development of cognitive, intrapersonal, and interpersonal dimensions of global perspectives, they implicitly called for preparation programs and professional development efforts to prepare leaders to holistically develop school leaders so they are informed by critical reflection that is situated in the cultural, political, and moral contexts of schooling (CCSSO, 2008). Responding specifically to the contexts in which schooling takes place, ISLLC Standard 6 states, "A school administrator is an educational leader who promotes the success of all students by understanding, responding to, and influencing the larger political, social, economic, legal, and cultural context" (CCSSO, 2008, p. 6). Similar to the 2008 ISLLC Standards used to assess principal preparation programs are the Educational Leadership Constituent Council (ELCC) Standards, developed for the National Council for Accreditation of Teacher Education (NCATE) under the auspices of the 
National Policy Board for the Educational Administration (NPBEA). First published in 1995 as Guidelines for Advanced Programs in Educational Leadership, the ELCC Standards aimed to help current and future school administrators meet the changing demands of society and schooling.

Cambron-McCabe (1993) called for the inclusion of this in preparation programs as they argued that school administrators must not only acquire an understanding of schools as sites of cultural conflict but also understand how they in their official roles legitimate specific perspectives and practices. Cambron-McCabe stated that school leaders must be able to assess schooling critically to illuminate the structures and practices that disempower. Additionally, according to Cambron-McCabe they must see leadership, not as management, but as a means for working toward the transformation of the school to advance social justice and a democratic school culture.

In Leadership for Social Justice (2010), Marshall and Oliva argue that future school leaders in the preparation program are continually confronted with views, or ways of seeing that challenge their long-held beliefs about schooling, culture, power, and social justice. Through critical reflection and questioning, leaders will come to understand their role in shaping the nature and purposes of schooling. They lament that educators too often see current practices as neutral and do not examine the appropriateness of the practices of the assumptions that drive them and, accordingly, direct attention to improving the existing practices rather than changing them.

Marshall and Oliva (2010) argue that the challenges of demographics and of inequities in the schools are chronic and remain unresolved by years of traditional practice, scholarship, theory, and professional training in educational administration. According to Marshall and Oliva (2010), recent attempts in policies (e.g., No Child Left Behind) and licensure (e.g., Interstate School Leaders Licensure Consortium) for educational administrators set an expectation for equitable outcomes, yet, they do not "connect the dots to integrate social justice-oriented methods, strategies, and training. As a consequence, they believe that social justice learning is not well incorporated into educational practice (p. 11).

\section{Data Sources and Methods}

\section{Research Design}

The methodological approach is a case-study in which qualitative and quantitative methods are combined. These mixed methods data-gathering techniques were the Global Perspectives Inventory (GPI) and a follow-up reflective open-ended survey. The GPI, a 46 item survey instrument designed 
to comprehensively measure respondent's global perspective, was developed by Braskamp, Braskamp, Merrill and Engberg. The participants were fortyfour graduate students from over three years 2008, 2009, and 2010 who were enrolled in Loyola University Chicago's graduate level school administration program and participated in a two-week study abroad class in Rome, Italy. These participants voluntarily took part in the GPI and the follow-up survey.

Students were given a pre-test and a post-test GPI to measure their development resulting from the two-week study abroad Rome program. The tests were administered a week before they left for Rome and then during one of the last days of the program. After compiling data, we used the "Interpretive Guide and Norms for the Global Perspective Inventory" for analysis and then compared the GPI from the graduate programs to undergraduate programs to demonstrate the impact of a short-term graduate study abroad experience.

The other portion of the research involved a follow-up reflective openended survey which was sent to the same forty-four students who attended the two-week Rome experience during 2008, 2009, or 2010. The survey consisted of four questions that specifically targeted two scales from the GPI: Intrapersonal/Identity and Interpersonal/Social Responsibility. These two were highlighted since they resulted in the most significant student development, as measured by the GPI, over the two-week period. In the students' responses, they were able to describe how personal development ias a result of their Rome experience then manifested in their day-to-day leadership. Fourteen subjects responded, yielding a $32 \%$ response rate. Through the reflective open-ended survey, the responses showed insight into the subjects' experiences since returning from Rome. The questions asked in the survey allowed the subjects to demonstrate how the Rome study abroad experience has affected them in their everyday lives as leaders.

\section{Instrument}

Global perspective, as it relates to the GPI, includes acquisition of knowledge, attitudes, and skills important to communication and holistic development of more complex epistemological processes, identities, and interpersonal relations as described by educational scholars (Braskamp, Braskamp \& Merrill, 2008). Development involves qualitatively different and more complex mental processes; acquisition involves an increasing quantitative collection of knowledge, attitudes, and skills.

The GPI is a survey instrument designed to comprehensively measure each respondent's global perspective, therefore, the instrument includes six scales - both developmental and acquisition scales within each of three dimensions: cognitive, intrapersonal, and interpersonal. As stated in the GPI 
"Interpretive Guide and Norms for the Global Perspective Inventory" the two cognitive scales are Knowing (development) and Knowledge (acquisition); the two intrapersonal scales are Identity (development) and Affect (acquisition); and the two interpersonal scales are Social Responsibility (development) and Social Interaction (acquisition) (Braskamp, Braskamp \& Merrill, 2010).

\section{Cognitive Scales}

Cognitive/Knowing. The Cognitive/Knowing scale focuses on how people know, not what they know. Development is indicated by how one thinks about cultural experiences. According to Hammer, Bennett, and Wiseman (2003), "The crux of development of intercultural sensitivity is attaining the ability to construe (and thus to experience) cultural difference in more complex ways" thus they view the knowing dimension as the foundation for intercultural sensitivity development (p. 423).

Cognitive/Knowledge. The Cognitive/Knowledge scale measures respondents' acquisition of confidence regarding what they know. Chen and Starosta (1996) and Gudykunst (2003) assert that what people know, or knowledge, is equally as important as epistemological development to a global perspective. Chen and Starosta (1996) contend that intercultural awareness, as the cognitive domain of their intercultural communication competence model, "emphasizes the changing of personal thinking about the environment through the understanding of the distinct characteristics of one's own and the other's cultures" (p. 354).

Intrapersonal/Identity. King and Baxter Magolda (2005) and Landreman (2003) describe the intrapersonal domain of intercultural maturity and intercultural consciousness, respectively, as including an identity development process. Similarly, Bennett and Bennett (2004) echo that "the development of general intercultural sensitivity is paralleled to a large extent by identity development" (p. 158). Therefore, people with a more developed global perspective would require a developed sense of their own identities. Chickering and Braskamp (2009) noted "identity formation must be enriched by more wide-ranging experiences, knowledge and insights” (p. 2). The Intrapersonal/ Identity scale measures participants' degree of acceptance of their own cultural background and the extent to which it informs their personal values and sense of self.

Intrapersonal/Affect. Some theorists (Bennett, 1993: Chen \& Starosta, 1996,: Chavez et al., 2003) see the intrapersonal dimension as an affective process, but others (Landreman, 2003) regard it as both identity and emotions. Landremen (2003) posits, "Coming to an understanding of multicultural issues, intercultural interactions, systems of oppression and social justice 
work is rife with feelings (e.g., anxiety, fear, shame, guilt, sadness and anger)" (p.28). As an affective process, the GPI's Intrapersonal/Affect scale measures respondents' acquisition of emotional comfort (including self-confidence) with situations that are different from or challenge their own cultural norms.

Interpersonal/Social Responsibility. King and Baxter Magolda (2005) include an interpersonal domain in their holistic model of intercultural maturity, which describes socio-relational development that "involves the ability to interact effectively and interdependently with diverse others" (p.579). Among others, they relate the development in this domain with the work of Chickering and Reisser (1993) and Gilligan (1982). Chickering and Reisser's seven vectors of psychosocial development include a vector of moving through autonomy toward interdependence. Autonomy is characterized by emotional and personal independence, such as solving problems in a self-directed manner. Interdependence is marked by a commitment to the welfare of the larger community, with the larger community now being a global and pluralistic one. The Interpersonal/Social Responsibility scale measures students' level of commitment to interdependent living and the common good (Braskamp, Braskamp, Merrill \& Engberg, 2010).

Interpersonal/Social Interaction. Several theorists (Bennett,1993; Chen \& Starosta, 1996; Chavez et al., 2003) describe the interpersonal domain as behavioral or as a matter of skill acquisition. For the Interpersonal/Social Interaction scale, the respondents' acquisition of and desire for exposure to people with cultural backgrounds different from their own is measured.

For this study, the GPI was used as a pre-test and post-test for assessing the effectiveness of the two-week study abroad program in fostering the development of global perspectives in students in the administration preparation program. Students responded to a reflective open-ended survey that described how the development in global perspectives during the Rome course (as measured by the GPI) were manifested in their day-to-day leadership.

\section{Case Study: Administrator Preparation Study Abroad Course}

\section{Course Description}

Forty-four graduate students over three years 2008, 2009, and 2010 who were enrolled in Loyola University Chicago's graduate level school administration program participated in a two-week study abroad class. The university maintains its own campus in Rome, Italy. The students enrolled in a three credit course: Instructional Leadership: Cultural Context for Informed Decision Making. It was the Rome-based option to a required on-campus 
instructional leadership course. This course used the historic sites of Rome as the "classroom" to discover the cultural components of Western Civilization and through them to interpret the fundamental issues at stake in current educational controversies. Seeing the culture objectified in the sites of Rome provided the basis for reflecting on why the current educational conflicts represent long-standing issues deeply embedded in our culture.

Specifically, the course objectives were:

1. Visit important locations in Rome which display issues that continue to be present in schools today (Roman Forum, Coliseum, Capitoline Hill, Pantheon, Jewish Ghetto, Tiber Island, St. Peter's Square and Basilica, Piazza Minerva, Pantheon, etc).

2. Reflect on current crucial educational issues to understand them as part of the fabric of Western Civilization and therefore as part of our heritage, such as: conflicting educational ideologies, gender equity, definition of shared identity, historical honesty, cleansing the past, and creation and consequences of ghettoes.

3. Present pros and cons of current educational debates such as: Is it ever necessary to create schools or classroom settings that separate students by gender? Which and whose values should the public schools teach the young, and why? Should schools emphasize America's cultural diversity or the shared aspects of American culture?

4. Examine one's own school/district in terms of how the issues raised are manifested in the school's explicit, implicit, and null curricula.

5. Determine implications for instructional leadership and change, enlightened by knowledge of the cultural heritage of an issue and its current manifestation.

This course was also designed to enable students to explore short-term intercultural immersion as Rome became each student's "learning laboratory" and served as the immediate cultural context for the exploration of the study. Students had the opportunity to systematically reflect on the reality of their own experience studying in Rome and to develop holistically in the cognitive, intrapersonal and interpersonal domains in relation to the topics that the course addressed. These experiences and reflections were recorded in daily journals which students maintained during site-based classes, engagement in the city, and week-end travel. 


\section{Goals Linked to the Cognitive, Intrapersonal and Interpersonal Domains}

Specific goals or "desired ends" of student development were linked to the cognitive, intrapersonal and interpersonal domains. The goals were:

\section{Cognitive}

1. Discover, become aware of, and better understand diverse perspectives, worldviews, social interactions, values, and cultural practices.

2. Understand one's own cultural background when compared to another.

3. Increase awareness of self and "other" and boundaries of tolerance. Examine education's response to fundamental difference.

4. Understand national destiny and historical honesty. Be aware of how the school curriculum treats expressions of historical tragedy, healing, and forgiveness.

5. Examine how perceptions about "the other" are constructed, particularly in the school setting.

5. Examine the repercussions of constructed perceptions of "the other", particularly in the school setting-better understand education's role in identifying who will be in positions of influence over the well-being of society.

6. Analyze ways to manage conflictive perceptions and cultural difference in the school setting-better understand conflicting educational ideologies and how they define the valued adult citizen.

\section{Intrapersonal}

1. Through study of new and different interactions with American peers, and Italian citizens, become conscious of, analyze, and gain a new perspective on one's own world views.

2. Increase self-confidence in negotiating cultural difference.

3. Construct and trust in one's self-identity through comparisons with diverse others.

\section{Interpersonal}

1. Increase ability and comfort in interacting with persons from different cultural backgrounds, especially in one's role as a school leader. 
7. Ability to assist others in adapting to various situations representing cultural difference, especially in one's role as a school leader.

8. Develop acceptance, tolerance, and respect of others with perspectives, values, worldviews, and social and cultural practices different from one's own.

9. Assist others to develop acceptance, tolerance and respect of others with perspectives, values, worldviews, and social and cultural practices different from one's own, especially in one's role as a school leader.

\section{GPI Results}

The means (average scale scores) for each of the six scales - two for each of the dimensions - Cognitive, Intrapersonal, and Interpersonal-is presented for the pre-test and post-test. The higher the mean-score, the more the group is considered to have a multicultural or global perspective i.e., that they are more apt to express the view of a global citizen. The GPI was purposefully "designed to comprehensively measure each respondent's global perspective" (Merrill, Braskamp \& Braskamp, in press, p.2) A global perspective is the capacity for a person to think with complexity taking into account multiple perspectives, to form a unique sense of self that is value-based and authentic, and to relate to others with respect and openness, especially with those who are not like him or her. Additionally, a global perspective "includes an individuals' sense of people, nation, and world beyond themselves" (Merrill, Braskamp \& Braskamp, in press, p.2).

Initially, we compared the differences of the GPI results between pre-tests and post-tests over the three summer sessions from 2008, 2009 and 2010 (see Table 1). These results allowed us to identify areas of strength and weakness in each class and also common themes. After the summer program in 2008, students' showed large areas of growth in Knowledge (Cognitive domain) and Identity (Intrapersonal domain). This indicated that students understood cultural differences and became more aware of how their unique characteristics make up their own identities. In 2009, the largest area of growth was in the Knowing (Cognitive domain) meaning students learned how to view their own perspectives and values in the big picture. Finally, the results from 2010 demonstrated the largest area of growth of all the three years in Affect (Intrapersonal domain). Specifically, they gained a new level of respect and acceptance for cultural perspectives different from their own and approached new situations with confidence.

In order to fully understand the impact of a two-week study abroad 
program, we then compared our results with 715 undergraduate students who studied abroad for a semester in over 20 programs who have completed the GPI. We examined the differences between pre-tests and post-tests of the graduates compared to those differences of the undergraduates (See Table 2). Since we were using a large sample of undergraduates, we decided that a minimum difference of .10 was necessary to show a significant development in the graduate students. As shown in Table 2, the graduate students showed a greater change in all domains and studied abroad for a shorter amount of time. We speculated this was a result of several factors: graduate students' age, maturation, and expectations of the study abroad experience. Additionally, calculating the average over three years for the two different populations demonstrated the strong learning curve for graduates who studied abroad for two weeks versus the undergraduates who studied abroad for a semester (See Table 3). This data is significant since to date, only this study has assessed the GPI on the graduate student population.

\section{Follow-Up Qualitative Survey}

For the reflective open-ended survey portion of the research, forty-four students were sent an electronic survey in September of 2010. Of the forty-four students, $32 \%$ responded; specifically, five students from 2008, four students from 2009, and five students from 2010. Four questions were posed representing Intrapersonal/Identity and Interpersonal/Social Responsibility since these scales were manifested in their day- to-day leadership. The graduate students (student leaders) had the most significant growth compared to the national norm of undergraduate students in the areas of intrapersonal/identity and interpersonal/social responsibility. The intrapersonal/identity scale represents levels of awareness of one's unique identity and degree of acceptance of one's ethnic, racial, and gender dimensions of one's identity. Interpersonal/social responsibility is characterized by emotional and instrumental independence, such as solving problems in a self-directed manner. Interdependence is marked by a commitment to the welfare of the larger community, with the larger community now being a global and pluralistic one. Answers to the questions represent several themes the students carried with them into their everyday lives. There were a few instances where students did not answer several of the questions, in those cases the numbers are represented as NA in the graphs.

The first question asked was related to the intrapersonal/identity scale and we sought to learn about specific experiences that occurred after their time in Rome where the individual felt extreme confidence. We asked them: Since you returned from your School of Education Rome experience, please describe a situation in which you felt confident in a completely new situation. 
Of the responses we received, there were four themes that arose from the subjects' answers. In the first theme, an individual pointed out their new appreciation for a variety of peer adult learners. The second theme exposed that in $50 \%$ of the respondents, a new job-related role or assignment resulted after their experience in Rome. In some cases, the individual sought out new opportunities and in others they were presented with a new role and decided to act on it. Twenty-one percent fell under the third theme that identified with a renewal of religious convictions in their everyday life after Rome. The remaining $21 \%$ of respondents acknowledged that they had experiences which gave them increased comfort, interaction, and engagement with new cultures and environments. See Chart 1 for representation of each theme across the sample population.

Through the second question we related the focus of intrapersonal/ identity scale directly to the students' experience in Rome by asking: How did your Rome experience prepare you to be confident in a completely new situation? Four new themes were represented in the respondent's answers in the open-ended survey. One of the former students acknowledged that she learned it is okay to have discomfort in new situations, this being the first theme. A second theme was identified in $29 \%$ of the responses which related to the former students finding their spirituality or calling as a result of their Rome experience. Another $21 \%$ of respondents stated that the Rome experience gave them the ability to recognize and appreciate new perspectives different from their own. Finally, the fourth theme, with the highest percentage of responses at 36\%, noted that individuals used their new knowledge to become successful and capable of navigating new challenges. Chart 2 outlines the responses to this particular question by the four themes.

The next two questions related to the interpersonal/social responsibility scale from the GPI which is one's level of interdependence and social concern for others. In the first question related to this scale, we asked respondents: Since you returned from your School of Education Rome experience, please describe a situation when you stood up for the rights of others. Three themes emerged in the former students responses. For the first theme, 29\% of respondents reported situations where they intervened personally to effect changes when the rights of others were being violated. Thirty-six percent of the former students identified with the second theme by noting that after returning from Rome they experienced a situation where they confronted others in a power or decision-making position to be an advocate for the rights of others. The third and final theme focused on experiences where $29 \%$ of former students provided understanding and knowledge to individuals in a situation where cultural differences were being judged because of pre-conceived assumptions. It is our 
hope and belief that the lessons taught in Rome gave the students newfound confidence and the ability to recognize their own social responsibility. See Chart 3 for the graphical analyses regarding this question and the three themes associated with it.

The final question related to the interpersonal/social responsibility scale in our survey asked the former students: How did your Rome experience influence your decision to intervene? Be specific. There were three themes associated with this question, the first was students understood that the marginalized are treated as less and that understanding gave them strength and voice to stand up for others. Fifteen percent of the respondents identified with theme one which exemplifies how Rome impacted them and gave them a voice in difficult situations. The second theme was represented by $22 \%$ of respondents and it correlated to the student's inability to remain silent, defined as: Students learned that silence is a choice, and choose not to remain silent. The majority of former students, 50\%, fell under the third theme; students learned that informed leaders have the responsibility to serve as protectors for those who cannot protect themselves. Chart 4 illustrates the three themes and their relationship to the former students' responses.

The follow-up open-ended survey asked four questions, designed to demonstrate how the study abroad experience influenced each individual's life after Rome. This transfer of lessons to skills is the more important aspect of international education, and it is the reason why students seek this experience, with the expectation that they will return to their hometowns possessing a new fresh perspective.

\section{Discussion}

In the $21^{\text {st }}$ century, in an era of wars, terrorism, natural disasters, financial uncertainty and high-stakes testing, educational leaders are faced with even more daunting decision-making difficulties than in a more tranquil period. Educational leaders now face profound decisions regarding their classrooms, schools, and school districts, in an ever-changing and challenging world. Beyond the typical decisions they must make, they also need to take into account evacuation plans, psychological assistance, conflict resolutions, and global events and threats that impact their communities. According to Shapiro and Gross (2008) the most difficult decisions are those that require dealing with paradoxes and complexities. Today's educational leaders must be equipped to lead during turbulent times.

These findings suggest that the study abroad experience helped the participants to develop honest personal reflection, comfort with questioning their prior beliefs and assumptions, and critical thinking as the basis for a larger 
and more adequate view of their roles and responsibilities as school leaders in these turbulent times. As one participant recounted, "My Rome experience prepared me to see that I am capable of meeting new challenges of leadership. The challenge of speaking in front of people, dealing with a group of people who did not share my same work ethic, confronting an unpleasant task and working through the situation helped me to see that I can be a mentor/leader to others."

In the educational leadership discipline, researchers increasingly recognize and acknowledge the need to improve practice and student outcomes for minority, economically disadvantaged, female, gay-lesbian, and other students who have not traditionally been served well in schools (Brunner, 2000: Skrla, Reyes \& Scheurich, 2000). Today's educational leader must assume the role of an activist, inspired not just by an intellectual ideal, but also by moral outrage at the unmet needs of students and a desire for a caring community where relationships matter.

Our findings suggest that the study abroad experience developed the school leader's ability to delve deeply into social justice issues requiring them to challenge the status quo and traditional pattern of privilege, and encourage them toward becoming advocates of equity-oriented leadership. Responding on how the Rome experience influenced their decision to intervene for the rights of others, one participant reported, "Our discussions in class, the history I learned on our explorations and visits of ancient Rome, gave me the desire to speak up and address an issue that previously I probably would have stayed silent about. My feeling now is I have an obligation to work for better care and dignity of our people. They are not in a position to do so." Another participant reflected, "My experience in Rome reminded me that cultural affiliation has significant impact on who we are and can even affect our educational goals. However, I was also reminded that everyone is an individual and has unique goals and aspirations despite where they come from. I may have known these simple truths before Rome, but my experience abroad gave me the confidence to speak openly about these issues in a way I was unable to before this experience."

And finally, one participant reported, "One of the salient points learned in my Rome experience is that we as educational leaders make choices daily on whether or not we are going to be advocates of social justice: silence is a choice. After Rome, I had more confidence, self-assurance, and conviction to be socially just. The experience in Rome is not as that of a tourist, but as an apprentice; learning, absorbing an experience, and growing as a whole person. My Rome experience influenced me to intervene by giving me an opportunity to grow and view myself in a new context and perspective." 
The results of this study add to a growing body of research documenting the effects of the study abroad experience. These findings suggest that the study abroad experience can sharpen the aims and develop opportunities for educational leaders for the complex, interconnected knowledge-based world of the $21^{\text {st }}$ century, which is characterized by global diversity and socioeconomic stratification. The results also imply that today's educational leaders "need to become ever more competent in understanding, talking with, relating to and working with persons who differ widely" from themselves (Braskamp \& Sobania, 2009, p. 1)

The results from the GPI and reflective open-ended survey provide evidence that opens up the conversation about how to best prepare school leaders to become global citizens in a complex and pluralistic world. This paper proposes a new taxonomy that includes the study abroad experience for the development of global perspectives in school leaders. Educational leadership programs can accelerate progress towards enacting this vision by becoming more intentional about their aspirations and about the practices they will put in place to achieve this.

\section{References}

Astin, A. W. (2001). What matters in college? Four critical years revisited. San Francisco: Jossey-Bass.

Bennett, J. M., \& Bennett, M. J. (2004). Developing intercultural sensitivity: An integrative approach to global and domestic diversity. In D. Landis, J. M. Bennett, \& M. J. Bennett (Eds.), Handbook of intercultural training (pp. 147-165) (3 $3^{\text {rd }}$ ed.). Thousand Oaks, CA: Sage.

Bennett, M. J. (1993). “Towards Ethnorelativism: A Developmental Model of Intercultural Sensitivity," in R.M. Paige, ed. Ed. Education for the Intercultural Experience. Yarmouth, Maine: Intercultural Press.

Braskamp, L. A., \& Sobania, N., (Fall 2009). Study abroad or study away: it's not merely semantics. Peer Review. Vol. 11, No. 4

Braskamp, L. A., Braskamp D. C. \& Merrill K. C. (2008). Global

Perspective Inventory (GPI): Its Purpose, Construction, Potential Uses, and Psychometric Characteristics. Chicago: Global Perspective Institute. http://gpi.central.edu.

Braskamp, L. A., Braskamp D. C. \& Merrill K. C. (2010) Interpretive Guide and Norms for the Global Perspective Inventory. Chicago: Global Perspective Institute. http://gpi.central.edu.

Braskamp, L. A., Braskamp D. C. \& Merrill K. C., Engberg, M. E. (2010).

Global Perspective Inventory. Chicago: Global Perspective Institute. http://gpi.central.edu. 
Brunner, C. C. (2000). Unsettled moments in settled discourse: Women superintendents' experiences of inequality. Educational Administration Quarterly. 36(1), 76-116.

Cambron-McCabe, N. (1993) Leadership for democratic authority. In M. Murphy (Ed.), Preparing tomorrow's school leaders: Alternative designs. University Park, PA: UCEA.

Chavez, A. F., Guido-DiBrito, F., \& Mallory, S. L. (2003). Learning to value the "other": A framework of individual diversity development. Journal of College Student Development, 44(4), 453-469.

Chen, G. M., \& Starosta, W. J. (1996). Intercultural communication competence: A synthesis. Communication Yearbook, 19, 353-384.

Chickering, A.W., Braskamp, L. A. (Fall 2009). Developing a global perspective for personal and social responsibility. Peer Review. Vol. 11, No. 4

Chickering, A. W., \& Reisser, L. (1993). Education and identity (2nd ed.). San Francisco: Jossey-Bass.

Council of Chief State School Officers. (2008). Interstate School Leaders Licensure Consortium: Standards for School Leaders. Washington, DC: Author.

Gilligan, C. (1982). In a different voice: Psychological theory and women's development. Cambridge, MA: Harvard University Press.

Gudykunst, W. B. (Ed.) (2003). Cross-cultural and intercultural communication. Thousand Oaks, CA: Sage.

Hammer, M. R., Bennett, M. J., \& Wiseman, R. (2003) Measuring intercultural sensitivity: The Intercultural Development Inventory. International Journal of Intercultural Relations. 27(4), 421-443. Interstate School Leaders Licensure Consortium

King, P. \& Baxter Magolda, M. (2005). A development model of intercultural maturity. Journal of College Student Development, 46(6), 571-592.

Landreman, L. (2003). A multidimensional model of intercultural consciousness: A reconceptualization of multicultural competence. Paper presented at the Annual Meeting of the Association for the Study of Higher Education, Portland, Oregon.

Lindsey, R, Roberts, M, and Campbelljones, F. (2005) The Culturally proficient school: An implementation guide for school leaders. Thousand Oaks, California: Corwin Press.

Merrill, K. C., Braskamp D. C. \& Braskamp, L. A. (In Press). Assessing individuals' global perspective. Journal of College Student Personnel. Marshall, C. \& Oliva M. (2010) Leadership for Social Justice: Making 
Revolutions in Education. Boston MA: Pearson Education, Inc.

Paige, R. M.. Jacobs-Casuto, M., Yershova, Y. A. \& DeJaeghere, J. (2003)

Assessing intercultural sensitivity: an empirical analysis of the Hammer and Bennett Intercultural Development Inventory. International Journal of Intercultural Relations, 27(4), 467-486.

Pascarella, E. T., \& Terenzini, P. T. (2005). How college affects students: Volume 2 A third decade of research. San Francisco: Jossey-Bass.

Shapiro, J. P., \& Gross, S. J., (2008) Ethical educational leadership in turbulent times: (Re)solving moral dilemmas. New York: Lawrence Erlbaum Associates.

Skrla, L., Reyes, P., \& Scherich, J. J. (2000). Sexism, silence, and solutions: Women superintendents speak up and speak out. Educational Administration Quarterly, 36(1), 44-75. 
Table 1 - Differences on GPI Scales: Summer Abroad LUC Grads

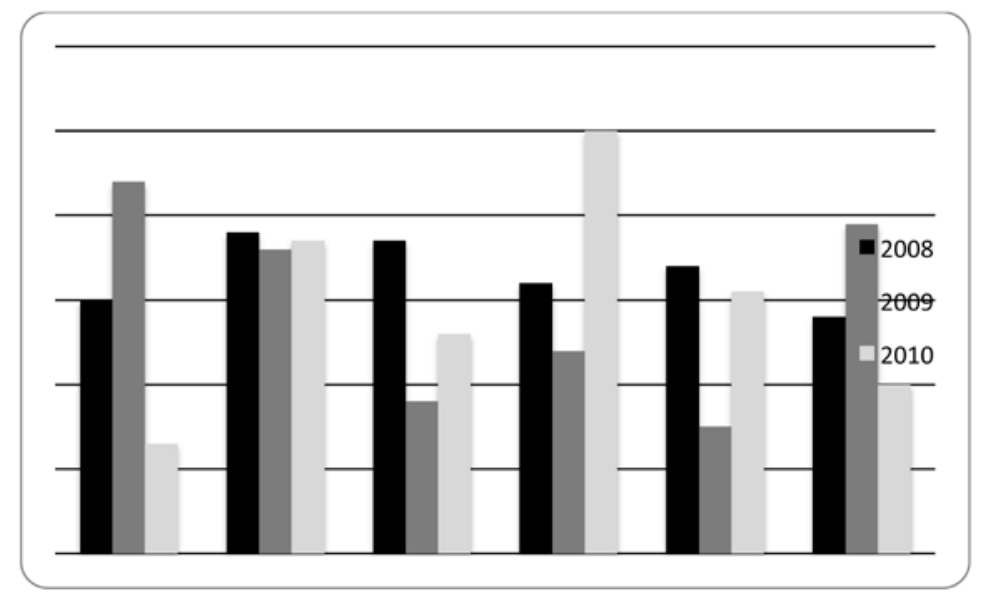

Table 2 - Means of Pre-test - Post-test changes on each GPI scale

\begin{tabular}{|c|c|c|c|c|c|c|c|}
\hline $\begin{array}{c}\text { Group \#I } \\
\text { Scale }\end{array}$ & $\begin{array}{l}\text { Length of } \\
\text { Study } \\
\text { Abroad }\end{array}$ & $\begin{array}{l}\text { Cognitive } \\
\text { Knowing }\end{array}$ & $\begin{array}{l}\text { Cognitive } \\
\text { Knowledge }\end{array}$ & $\begin{array}{c}\begin{array}{c}\text { Intra- } \\
\text { personal }\end{array} \\
\text { Identity }\end{array}$ & $\begin{array}{c}\begin{array}{c}\text { Intra- } \\
\text { personal/ }\end{array} \\
\text { Affect }\end{array}$ & $\begin{array}{c}\text { Inter- } \\
\text { Personal/ } \\
\text { Social } \\
\text { Interaction }\end{array}$ & $\begin{array}{c}\text { Inter- } \\
\text { Personal/ } \\
\text { Social } \\
\text { Responsibility }\end{array}$ \\
\hline $\begin{array}{c}\text { Change } \\
\text { (245) } \\
\text { Undergrad } \\
\text { Students } \\
2008\end{array}$ & Semester & .03 & .33 & .12 & .19 & .13 & .10 \\
\hline $\begin{array}{c}\text { Change } \\
\begin{array}{c}(470) \\
\text { Undergrad }\end{array} \\
\text { Students } \\
2009\end{array}$ & Semester & .10 & .31 & .16 & .13 & .15 & .05 \\
\hline $\begin{array}{c}\text { Change } \\
\text { (44) } \\
\text { Graduate } \\
\text { Students } \\
\text { Avg. } \\
\text { 2008-2010 }\end{array}$ & $\begin{array}{c}\text { Two } \\
\text { Weeks }\end{array}$ & .32 & .37 & .28 & .33 & .30 & .27 \\
\hline
\end{tabular}


Janis B. Fine and Krista W. MCNamara

Table 3 - Average Difference:

Summer Abroad LUC Grads vs. Semester Abroad LUC Undergrads

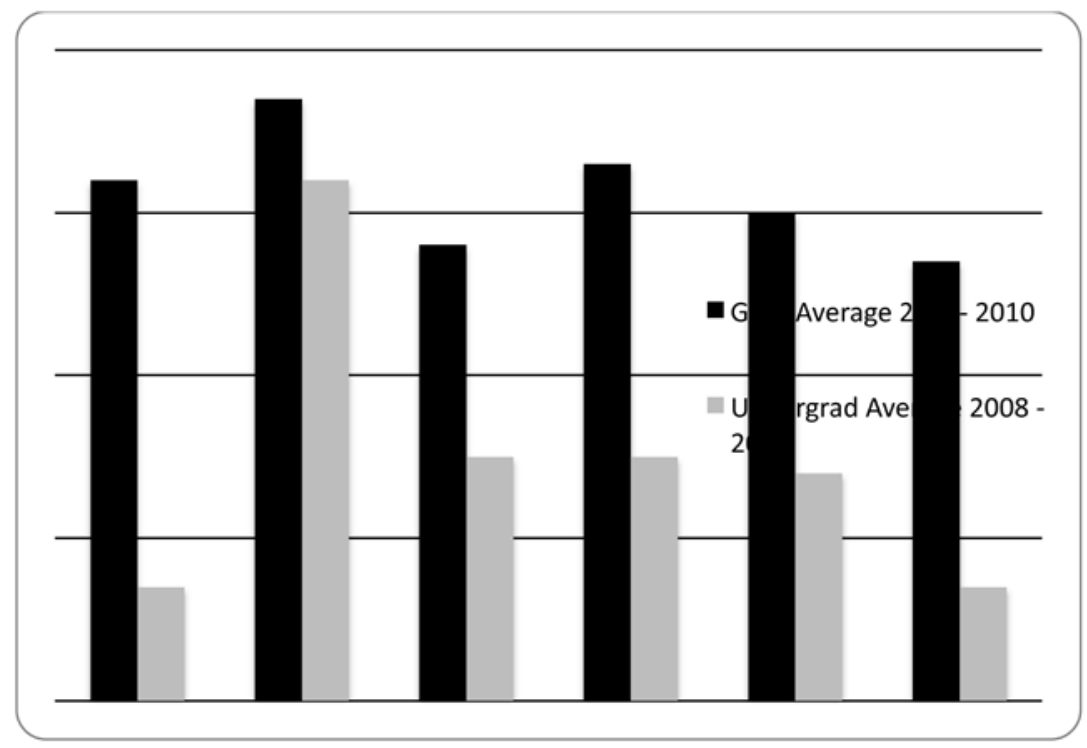

Chart 1

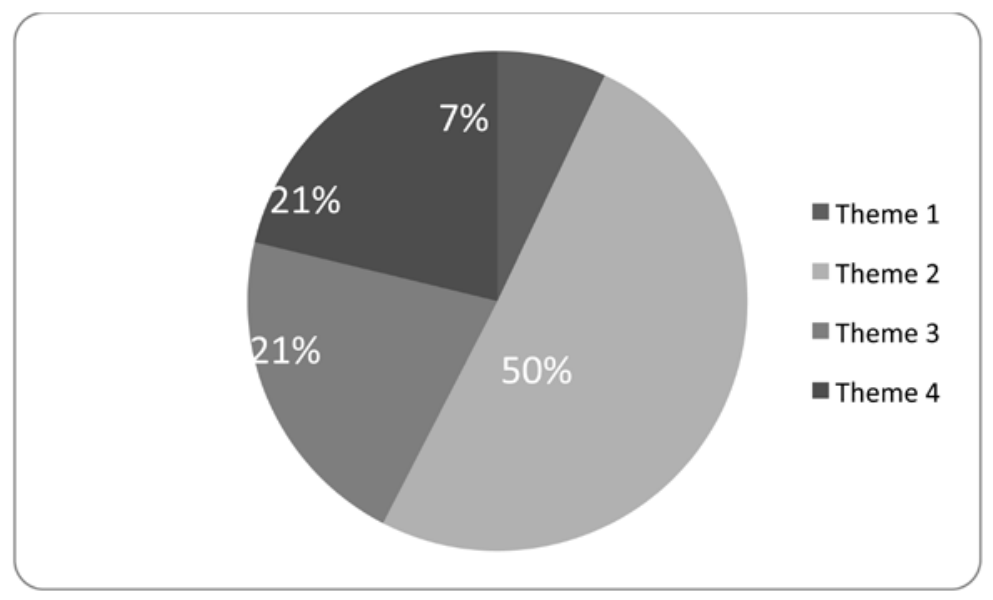




\section{Chart 2:}

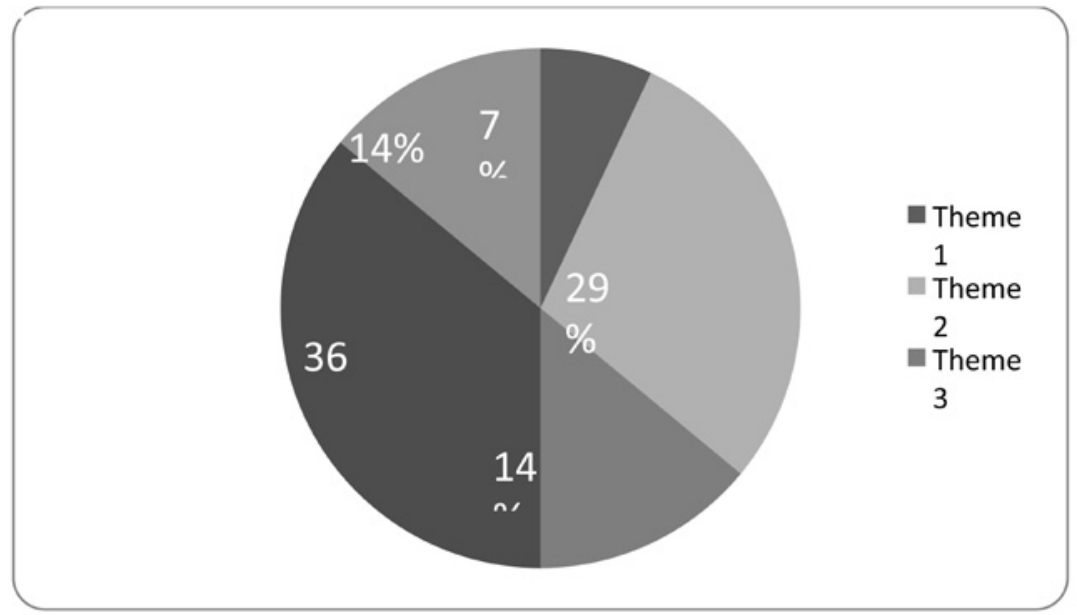

Chart 3:

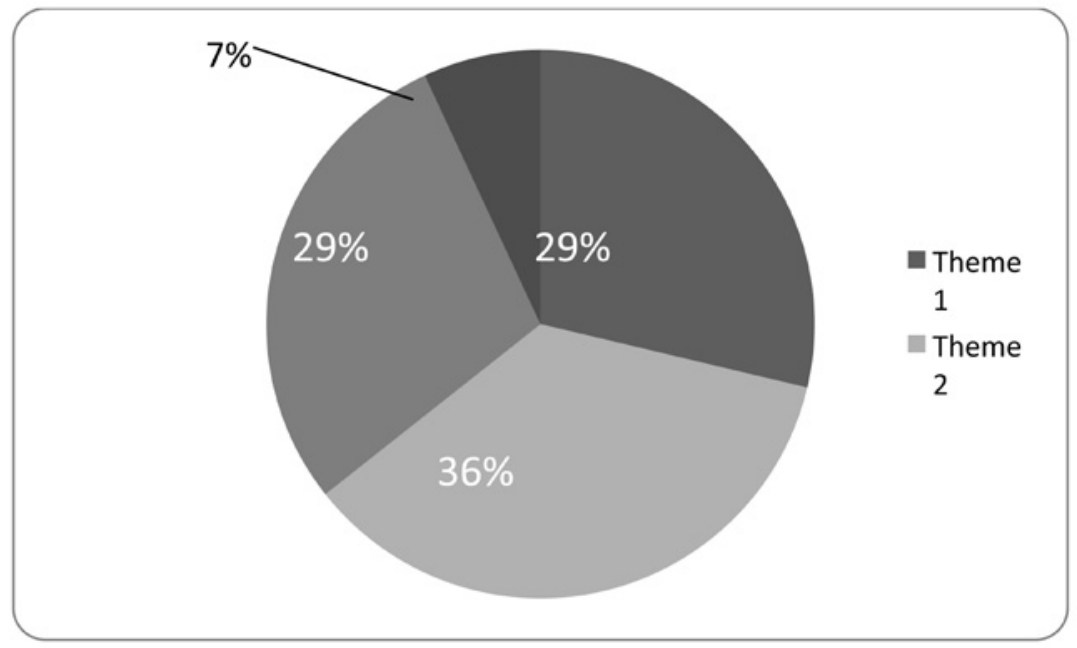




\section{Chart 4:}

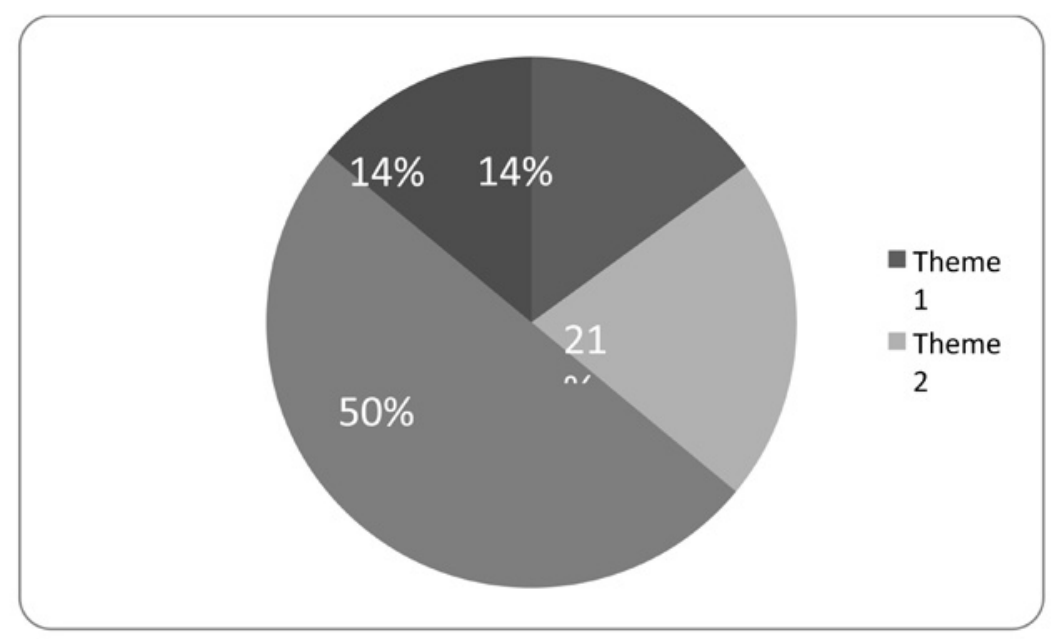

